\title{
A Novel Nanocomposite Membrane Combining BN Nanosheets and GO for Effective Removal of Antibiotic in Water
}

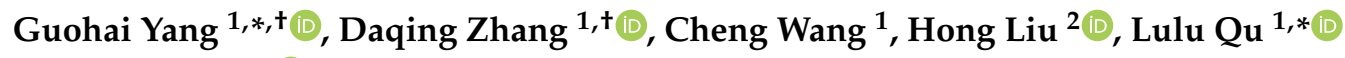 \\ and Haitao $\mathrm{Li}^{1, *(D)}$ \\ 1 School of Chemistry and Material Science, Jiangsu Normal University, Xuzhou 221116, China; \\ 15605227012@163.com (D.Z.); 18852121622@163.com (C.W.) \\ 2 Key Laboratory of Gas and Fire Control for Coal Mines (Ministry of education), China University of Mining \\ and Technology, Xuzhou 221116, China; liuhong2013@cumt.edu.cn \\ * Correspondence: yangguohai@jsnu.edu.cn (G.Y.); luluqu@jsnu.edu.cn (L.Q.); haitao@jsnu.edu.cn (H.L.) \\ + These authors contributed equally to this work.
}

Received: 27 January 2019; Accepted: 3 March 2019; Published: 6 March 2019

\begin{abstract}
Residual antibiotics in water have become a primary source of water pollution due to their misuse. Recently, membranes, produced by layered nanomaterials such as graphene oxide (GO), boron nitride (BN) and transition metal dichalcogenides, have been used in water purification, desalination and molecule separation as they are energy saving and simple to operate. The performance of membranes is closely related to their structure and the properties of the nanomaterials used. In this work, $\mathrm{BN}$ nanosheets (BNNSs) and GO were used to fabricate a two-dimensional nanocomposite membrane in order to improve the membrane's permeance. It should be mentioned that the corresponding equal mass of the pure GO membrane was almost impermeable for the antibiotic solution. Multi-walled carbon nanotubes (MWCNTs) were inserted into the GO layers to increase the interlayer spacing and adsorb more antibiotics from the water. The resultant MWCNTs/BNNSs/GO membranes showed improved permeance and stable sieving capability for the antibiotic and small species. Specifically, permeance reached $30.2 \mathrm{~L} \mathrm{~m}^{-2} \mathrm{~h}^{-1} \mathrm{bar}^{-1}$, which was much higher than pure GO membrane and the antibiotic rejection was $96.1 \%$.
\end{abstract}

Keywords: graphene oxide; boron nitride nanosheets; high permeance and selectivity; filtration membrane

\section{Introduction}

Antibiotics, which are widely utilized in medicine, poultry farming and food processing [1,2], have attracted considerable attention due to their abuse and their harmful effects on human health and the ecological environment [3,4]. The misuse of antibiotics induces DNA contamination and accelerates the generation of drug-resistant bacteria and super-bacteria [5-7]; thus, some diseases are more difficult to cure [8]. A number of studies have revealed that the level of antibiotics in the soil, air and surface water, and even in potable water, is excessive in many areas [9-11], which will ultimately accumulate in the human body via drinking water and then damage the body's nervous system, kidneys and blood system. Therefore, it is necessary to develop an efficient method to remove antibiotics present in water.

Membrane technology, which is characterized by being energy-saving, highly efficient and easy to operate, has been widely used in the last few decades. It has been applied in water desalination and purification, waste water treatment, gas separation, dialysis and so on. However, it is not easy to fabricate a robust membrane with high performance, high permeability, and high selectivity. Membrane performance is highly dependent on the materials used and their structure. 
Recently, two-dimensional (2D) nanomaterials, such as graphene oxide (GO) [12-14], boron nitride (BN) $[15,16]$, transition metal dichalcogenides [17-19], have been investigated in the membrane process due to their particular physical and chemical properties. For example, GO is appropriate for fabricating filter membranes due to its atomic thin thickness, lamellar structure and consequent specific properties, such as high chemical stability and specific surface, and its porous and rich oxygen-containing functional sites [20]. Moreover, GO-based membranes, using tunable interlayer spacing to intercept ions and contaminants in water, are most promising [13,21-23]. However, GO membranes do have some deficiencies. A number of methods and experiments have been performed to overcome the weaknesses of the original GO membrane, such as swelling or delamination in aqueous solutions and the tradeoff between selectivity and permeability [24]. A 2D heterostructure GO/g- $\mathrm{C}_{3} \mathrm{~N}_{4} @ \mathrm{TiO}_{2}$ membranes for water-oil separation with a permeance of $4536 \mathrm{~L} \mathrm{~m}^{-2} \mathrm{~h}^{-1} \mathrm{bar}^{-1}$ has been fabricated [25]. Although permeation of the $\mathrm{GO} / \mathrm{g}-\mathrm{C}_{3} \mathrm{~N}_{4} @ \mathrm{TiO}_{2}$ membrane is very high, the performance of the membrane in removing contaminants such as antibiotics and dyes is unknown. Thiourea (TU) was used as a crosslinker to connect adjacent GO layers and fabricate a graphene oxide framework (GOF) membrane for the separation of small molecules [26]. The prepared TU-GOF membrane has good sieving properties for small molecules, resulting in almost complete rejection of alcohol and ions in the gas, solvent, and saline separations; however, the permeance of the membrane is low. Therefore, the fabrication of an efficient membrane to eliminate antibiotics from water is essential.

$\mathrm{BN}$, another 2D nanomaterial which is known as "white graphene", has unique properties distinct from graphene. Its characteristics include strong oxidation resistance at high temperatures, excellent adsorption capability, no surface charge and special luminescence. BN nanosheets (BNNSs) are remarkable substrates for graphene, $\mathrm{MoS}_{2}$ layers and other 2D nanomaterials in electronic and optical applications. Recently, BN has been widely used in membrane research area [27-30].

In this study, BNNSs and GO were combined to construct a 2D nanocomposite and form a membrane using vacuum filtration. BNNSs act as both substrate and filter in the membrane and replace integrant GO nanosheets which could prevent the swelling of GO membrane in aqueous solution. The fabrication of BNNS is easier and more energy-saving than that of GO, so the prepared membrane is likely to be produced on a large scale. Moreover, multi-walled carbon nanotubes (MWCNTs), decorated with polydiallyldimethylammonium chloride (PDDA), were inserted into the BNNSs/GO to increase the interlayer space and enhance the absorbability of the membrane. The prepared MWCNTs/BNNSs/GO nanocomposite membrane was characterized and then used to eliminate the antibiotic tetracycline hydrochloride $(\mathrm{TCH})$ in water. Ultraviolet-visible (UV/Vis) spectrophotometry was utilized to detect the concentrations of TCH solution. The results show that the prepared membrane efficiently removed TCH in water with a quite high permeance of $30.2 \mathrm{~L} \mathrm{~m}^{-2} \mathrm{~h}^{-1} \mathrm{bar}^{-1}$.

\section{Experimental Section}

\subsection{Materials}

Concentrated sulfuric acid $\left(\mathrm{H}_{2} \mathrm{SO}_{4}, 98 \%\right)$, phosphorus penta-oxide $\left(\mathrm{P}_{2} \mathrm{O}_{5}\right)$, potassium persulfate $\left(\mathrm{K}_{2} \mathrm{~S}_{2} \mathrm{O}_{8}\right)$, potassium nitrate $\left(\mathrm{KNO}_{3}\right)$, potassium permanganate $\left(\mathrm{KMnO}_{4}\right)$, hydrogen peroxide $\left(\mathrm{H}_{2} \mathrm{O}_{2}\right.$, aq), hydrochloric acid $(\mathrm{HCl})$, polydiallyldimethylammonium chloride (PDDA, aq, $20 \mathrm{wt} \%$ ), hexagonal boron nitride (h-BN), TCH, and ethyl alcohol (EtOH) were purchased from Aladdin (Shanghai, China), graphite and MWCNTs (diameter 20-30 nm, length 10-30 $\mu \mathrm{m}$ ) were purchased from BoYu Material Company (Beijing, China), deionized water was purified using the Milli-Q reference system $\left(>18 \mathrm{M} \Omega \cdot \mathrm{cm}^{-1}\right.$, Billerica, MA, USA). All chemicals were used directly without further preparation.

\subsection{Fabrication of Graphene Oxide (GO) Dispersion}

GO was fabricated using the modified Hummers' method [31]. A mixed solution of concentrated $\mathrm{H}_{2} \mathrm{SO}_{4}(60 \mathrm{~mL}), \mathrm{K}_{2} \mathrm{~S}_{2} \mathrm{O}_{8}(4.2 \mathrm{~g})$ and $\mathrm{P}_{2} \mathrm{O}_{5}(4.2 \mathrm{~g})$ was heated to $80{ }^{\circ} \mathrm{C}$, and graphite powder $(5 \mathrm{~g})$ was added under continuous stirring for $4.5 \mathrm{~h}$. When the solution had cooled, the products obtained 
were filtered and washed with deionized water until no residual acid was present. The dried fluffy product $(5 \mathrm{~g})$ was then placed into concentrated $\mathrm{H}_{2} \mathrm{SO}_{4}(120 \mathrm{~mL})$ at $0{ }^{\circ} \mathrm{C}$, followed by the controlled addition of $\mathrm{KNO}_{3}(2.5 \mathrm{~g})$ and $\mathrm{KMnO}_{4}(16 \mathrm{~g})$ with the temperature below $10{ }^{\circ} \mathrm{C}$. The reaction was performed at $35^{\circ} \mathrm{C}$ for $2 \mathrm{~h}$, and continued for a further $2 \mathrm{~h}$ following the addition of deionized water ( $250 \mathrm{~mL})$. Subsequently, deionized water $(600 \mathrm{~mL})$ and $\mathrm{H}_{2} \mathrm{O}_{2}(30 \mathrm{~mL}, 30 \mathrm{wt} \%)$ were added to the solution, and allowed to stand overnight. Finally, the mixture was washed with $1 \mathrm{M} \mathrm{HCl}$ solution and deionized water to confirm the removal of metal ions and acid, then dried at $60^{\circ} \mathrm{C}$ for 2 days. The GO suspension at the concentration of $2 \mathrm{mg} \mathrm{mL}^{-1}$ was obtained after sonication. The GO suspension used in this study was all $2 \mathrm{mg} \mathrm{mL}^{-1}$.

\subsection{Fabrication of Polydiallyldimethylammonium Chloride-Multi-Walled Carbon Nanotubes (PDDA-MWCNTS) Dispersion}

PDDA solution (50 mg, $20 \mathrm{wt} \%$ ) was diluted with $60 \mathrm{~mL}$ of deionized water and sonicated for $10 \mathrm{~min}$, mixed with $10 \mathrm{~mL}$ MWCNTs $\left(1 \mathrm{mg} \mathrm{mL}^{-1}\right)$ solution and sonicated for another $30 \mathrm{~min}$, and then centrifuged for $30 \mathrm{~min}$ at $5000 \mathrm{rpm}$. The supernatant was collected and filtrated to obtain PDDA-MWCNTs. The PDDA-MWCNTs was rinsed with $60 \mathrm{~mL}$ deionized water and dried at $60{ }^{\circ} \mathrm{C}$ overnight. The mass of PDDA-MWCNTs was weighed accurately, then the PDDA-MWCNTs was dispersed in water by sonication. Finally, a homogeneous PDDA-MWCNTs dispersion at a concentration of $0.5 \mathrm{mg} \mathrm{mL}^{-1}$ was prepared, and the PDDA-MWCNTs solution used below was all $0.5 \mathrm{mg} \mathrm{mL}^{-1}$.

\subsection{Fabrication of Boron Nitride Nanosheets (BNNSs) Dispersion}

The BNNSs dispersion was prepared using commercial h-BN powder by ball milling [32] (planetary ball mill, QM-3SP2). Typically, the h-BN powder (0.5 g) and urea (30 g) were added to a ball mill cell and ball milled at $500 \mathrm{rpm}$ for $12 \mathrm{~h}$ at room temperature. During the high-energy ball-milling process, $\mathrm{BN}$ and urea particles were thoroughly mixed, and some small urea molecules may intercalate into the BN structure from the edges of BN layers. Powered by the energy of colliding balls, urea would decompose and lead to chemical bonding of $\mathrm{NH}_{2}$ group to few-layer $\mathrm{BN}$.

After ball milling, the product was washed with deionized water to remove urea. The collected BNNSs was dispersed in water by sonication, then the dispersion was centrifuged for $30 \mathrm{~min}$ at $2000 \mathrm{rpm}$. The supernatant was collected and filtrated to obtain BNNSs. Finally, BNNSs dispersion at a concentration of $2 \mathrm{mg} \mathrm{mL}^{-1}$ was prepared by dispersing solid BNNSs in water. The dispersion was then characterized by zeta potential, scanning electron microscopy (SEM), transmission electron microscopy (TEM) and atomic force microscopy (AFM). The BNNSs dispersion used below was all $2 \mathrm{mg} \mathrm{mL}^{-1}$.

\subsection{Fabrication of the Membrane}

Six mL of PDDA-MWCNTs dispersion was added into $2 \mathrm{~mL}$ of GO dispersion and stirring for $10 \mathrm{~min}$, then $4 \mathrm{~mL}$ of BNNSs dispersion was dropped into mixed solution under stirring. The final mixed solution was stirred at room temperature for $10 \mathrm{~min}$, followed by sonication for $10 \mathrm{~min}$, repeated 5 times. Then the mixed dispersion was used to fabricate the MWCNTs/BNNSs/GO membranes on a PVDF (polyvinylidene fluoride) membrane through vacuum filtration. The prepared membrane was used to filter the TCH solution and was characterized by SEM, TEM and X-ray diffraction (XRD). The total mass of the composite membrane was maintained at $15 \mathrm{mg}$. Specifically, the mass of PDDA-MWCNTs was constant at $3 \mathrm{mg}$ and total mass of GO and BNNSs was constant at $12 \mathrm{mg}$. The mass ratio of GO and BNNSs was changed to 5:1, 2:1, 1:1, 1:2, and 1:5 to optimize the performance of the membrane. Moreover, the corresponding pure GO membrane, pure BNNSs membrane and MWCNTs/GO membrane were also produced to detect their performance for the removal of TCH from water. Specifically, $2 \mathrm{~mL}$ of GO dispersion was used to fabricate pure GO membrane, and $4 \mathrm{~mL}$ of BNNSs dispersion was used to fabricate pure BNNSs membrane. The MWCNTs/GO membrane was produced by $2 \mathrm{~mL}$ of GO dispersion and $6 \mathrm{~mL}$ of PDDA-MWCNTs dispersion. 


\subsection{Filtration Experiment}

Five MWCNTs/BNNSs/GO membranes of equal weight (15 mg) were prepared under the same conditions, but the mass ratio of GO to BNNSs in the membrane was changed. The prepared membranes were used to filter $30 \mathrm{mg} \mathrm{L}^{-1} \mathrm{TCH}$ solution by vacuum filtration and the vacuum degree was stabilized at 0.9 bar. The volume of TCH solution was $10 \mathrm{~mL}$. The filter liquor was collected and detected by ultraviolet-visible (UV-Vis) spectroscopy. The rejection to TCH using the prepared membrane was calculated by the following formula: $\eta=\left(C_{0}-C\right) * C_{0}{ }^{-1 *} 100 \%=\left(A_{0}-A\right) * A_{0}{ }^{-1} *$ $100 \%$, where $\eta$ is the rejection of the membrane, $C_{0}$ and $C$ are concentration of TCH solution before and after filtration, $A_{0}$ and $A$ are maximal absorbance of $\mathrm{TCH}$ before and after filtration. The permeance of the membrane was calculated by the following formula: $J=V * S^{-1 *} T^{-1 *} P^{-1}$. Where $J$ is the permeance of the membrane, $V$ is the volume of TCH solution, $S$ is the area of the membrane, $T$ is the filtration time and $P$ is the vacuum degree. Moreover, different concentrations $\left(0.2-0.8 \mathrm{~mol} \mathrm{~L}^{-1}\right)$ of $\mathrm{NaCl}$ and $\mathrm{CaCl}_{2}$ solution were prepared to measure the effect of salts to the membrane performance. It is noted that the collected data were averages of three parallel tests. That is, three membranes were prepared for each condition at the same time.

\subsection{Characterization}

A scanning electron microscope (SEM) (Hitachi, Japan) and atomic force microscope (AFM) (Bruker, Germany) were used to observe the surface morphology and the thickness of the samples. A transmission electron microscope (TEM) (JEOL, Japan) was used to obtain the structures of the samples. X-ray diffraction (XRD) patterns (Shimadzu, Japan) of the samples were obtained to confirm the crystallographic properties, employing $\mathrm{CuK} \alpha$ radiation, $\lambda=0.15418 \mathrm{~nm}$. The zeta potential was measured with a SurPASS Electrokinetic Analyzer (Austria) with a clamping cell at 300 mbar. The UV-Vis spectrum (Thermo Fisher Scientific, Waltham, MA, USA) was used to monitor the concentration of the antibiotic.

\section{Results and Discussion}

\subsection{Characterization and Mechanism}

The BNNSs used in this work were characterized by SEM, TEM and AFM, and the morphology images are shown in Figure 1. In Figure 1a, delaminated BNNSs were wafer-like and piled up randomly. The diameter of the BNNSs ranged from 100 to $500 \mathrm{~nm}$ which was consistent with the TEM and AFM results (Figure 1b,c). Figure S1a shows that the thickness of BNNSs collected by AFM was about $1.5 \mathrm{~nm}$. These indicated that the BNNSs were successfully stripped from h-BN. The zeta potential of BNNSs dispersed in water was $-36 \pm 3 \mathrm{mV}$ which is similar with the literature [32]. Figure $1 \mathrm{~d}$ shows the surface morphology of the composite membrane. It can be seen that the surface of the membrane was rough due to the presence of BNNSs and MWCNTs. Moreover, the rough surface helped to retain the contaminant in water. The prepared GO was also characterized by SEM, TEM, and AFM (Figure S1b-d), which demonstrated the successful synthesis of single-layer GO.

The dispersion liquids of BNNSs, GO and modified MWCNTS, shown in Figure 2a, were used to build the skeleton of the composite membrane using vacuum filtration and the preparation process is shown in Figure $2 \mathrm{~b}$. After the modification with PDDA, a cationic polyelectrolyte, the positively charged MWCNTs dispersion was mixed with the negatively charged GO dispersion and stirred for $10 \mathrm{~min}$, then the negatively charged $\mathrm{BN}$ dispersion was dropped into the mixing system under stirring. In order to mix the dispersions evenly, the mixed liquid was stirred for $10 \mathrm{~min}$ and sonicated for $10 \mathrm{~min}$ (repeated five times) before vacuum filtration. GO and BNNSs were stacked on each other, and subsequently built the skeleton of the membrane which was the water transportation channel. 


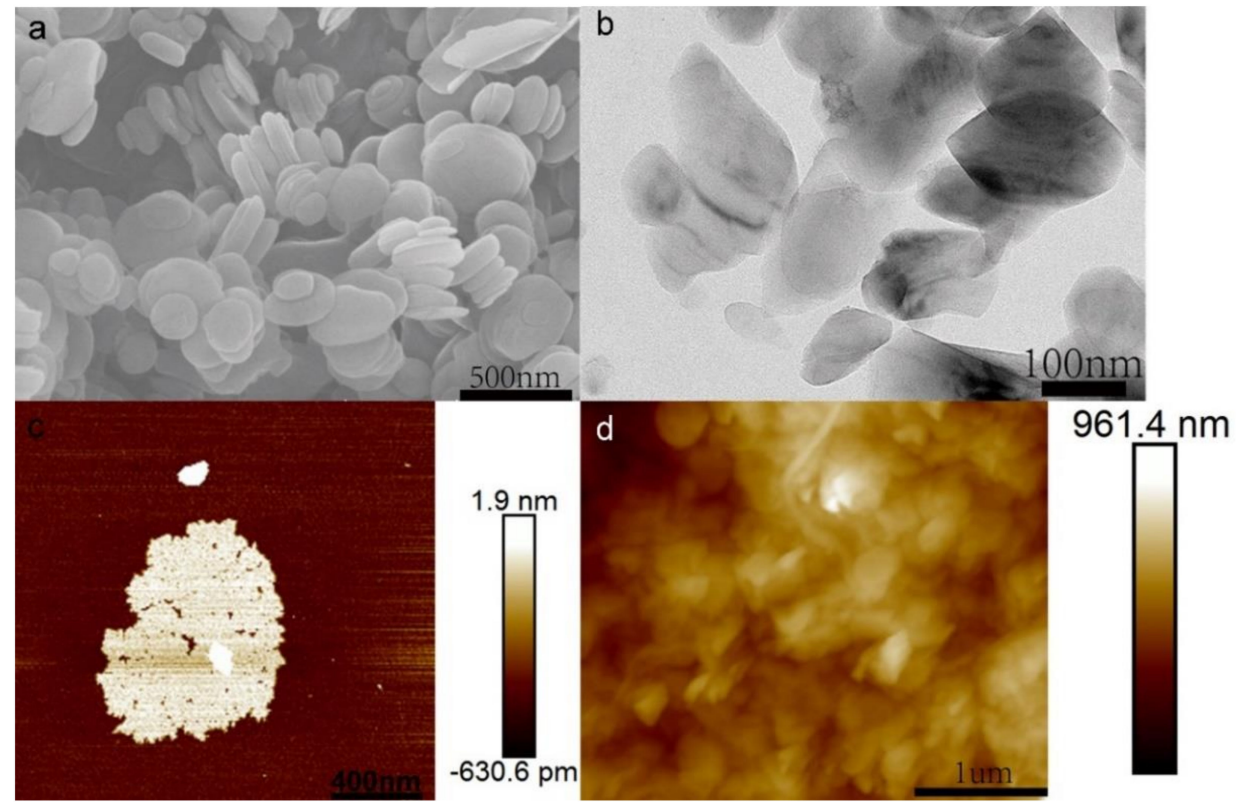

Figure 1. (a) Scanning electron micrograph (SEM), (b) transmission electron micrograph (TEM), and (c) atomic force micrograph (AFM) of boron nitride (BN) nanosheets. (d) AFM of the composite membrane.

a

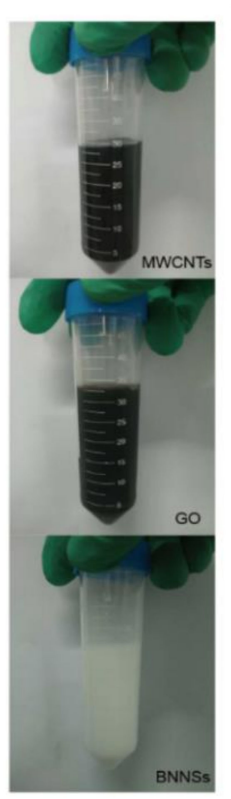

b
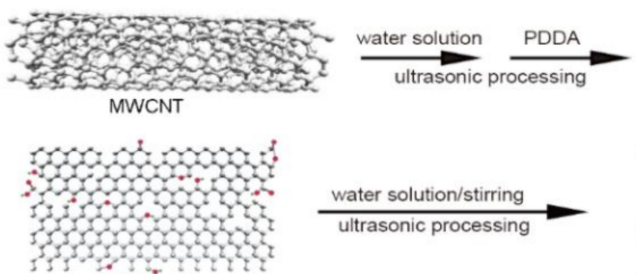

GO

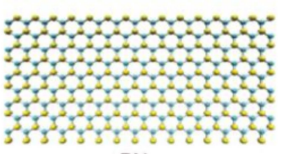

$\mathrm{BN}$
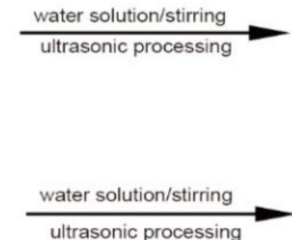

ultrasonic processing

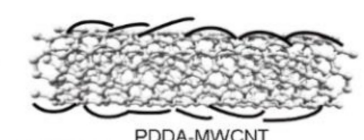

PDDA-MWCNT

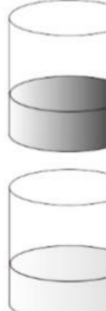

dispersion liquid

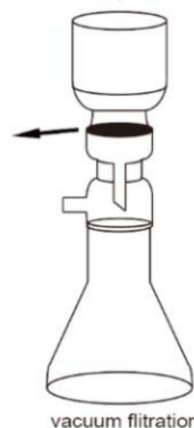

vacuum flitration

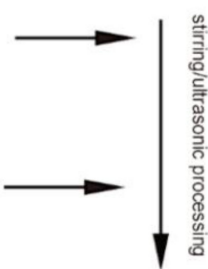

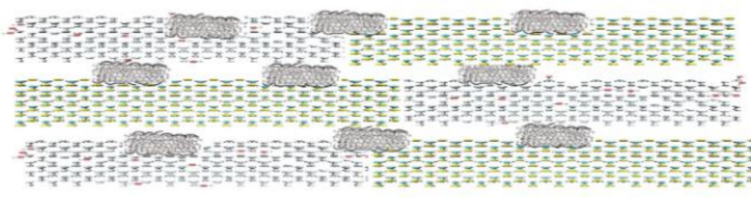

composite membrane

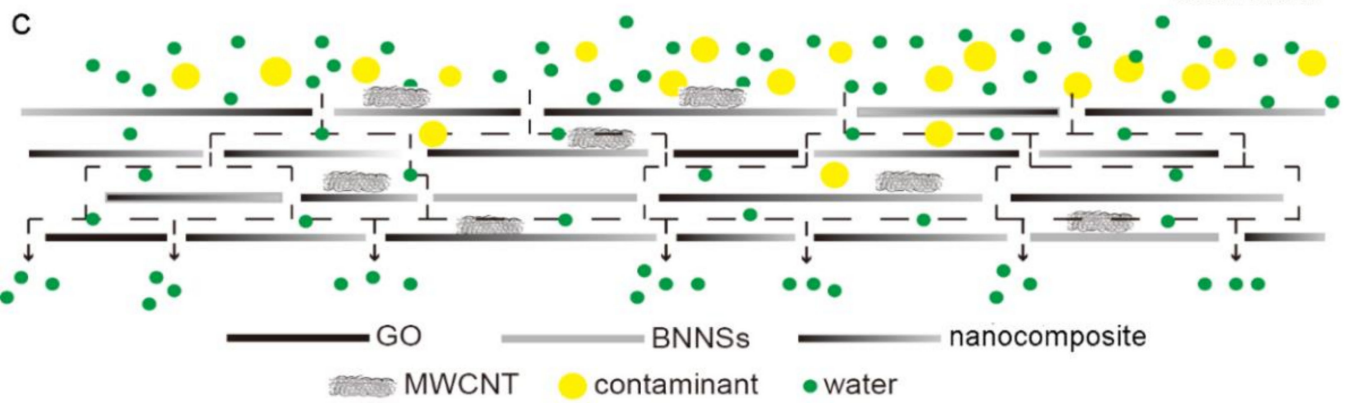

Figure 2. (a) A photograph of the prepared multi-walled carbon nanotubes (MWCNTs), graphene oxide (GO) and boron nitride nanosheets (BNNSs) dispersion. (b) Preparation flow chat of the membrane. (c) Illustration of the solute separation mechanism. 
An optical image of the MWCNTs/BNNSs/GO membrane is shown in Figure 3a and a commercial hydrophobic membrane was used as the substrate. It should be mentioned that the membrane was flexible and stable in water. In order to maximize the permeance of the membrane and obtain high contaminant molecule trapping, the mass ratio of GO to BNNSs was changed. The mass ratio of GO to BNNSs was 5:1, 2:1, 1:1, 1:2, and 1:5, respectively, and the corresponding membrane was denoted as Membrane- $X(M-X)$ where $X$ is the mass ratio of GO to BNNSs $(X=5,2,1,0.5,0.2)$. As observed in Figure $3 b-f$, the surface of the membrane became rough when the mass of GO was decreased. The membrane skeleton which formed the nanochannel was replaced by the BNNSs/GO nanocomposite. Thus, the larger interlayer space of the membrane led to a greater permeance. At the same time, the MWCNTs in the membrane helped to adsorb contaminants due to their nanostructure. The effect of MWCNTs on membrane performance was also determined (Figure S2). It was found that $3 \mathrm{mg}$ MWCNTs was optimal for membrane performance. The thickness of the composite membrane was simply adjusted by filtering different amounts of mixed dispersion (Figure 4). As shown in the image, the thickness of the membrane fabricated using $12 \mathrm{~mL}$ of mixed dispersion was $6.64 \mu \mathrm{m}$, while the membrane fabricated using $6 \mathrm{~mL}$ of mixed dispersion was $5.30 \mu \mathrm{m}$. It is possible that the skeleton of the thin membrane was looser. The membrane used in subsequent studies was fabricated using $12 \mathrm{~mL}$ of mixed dispersion.

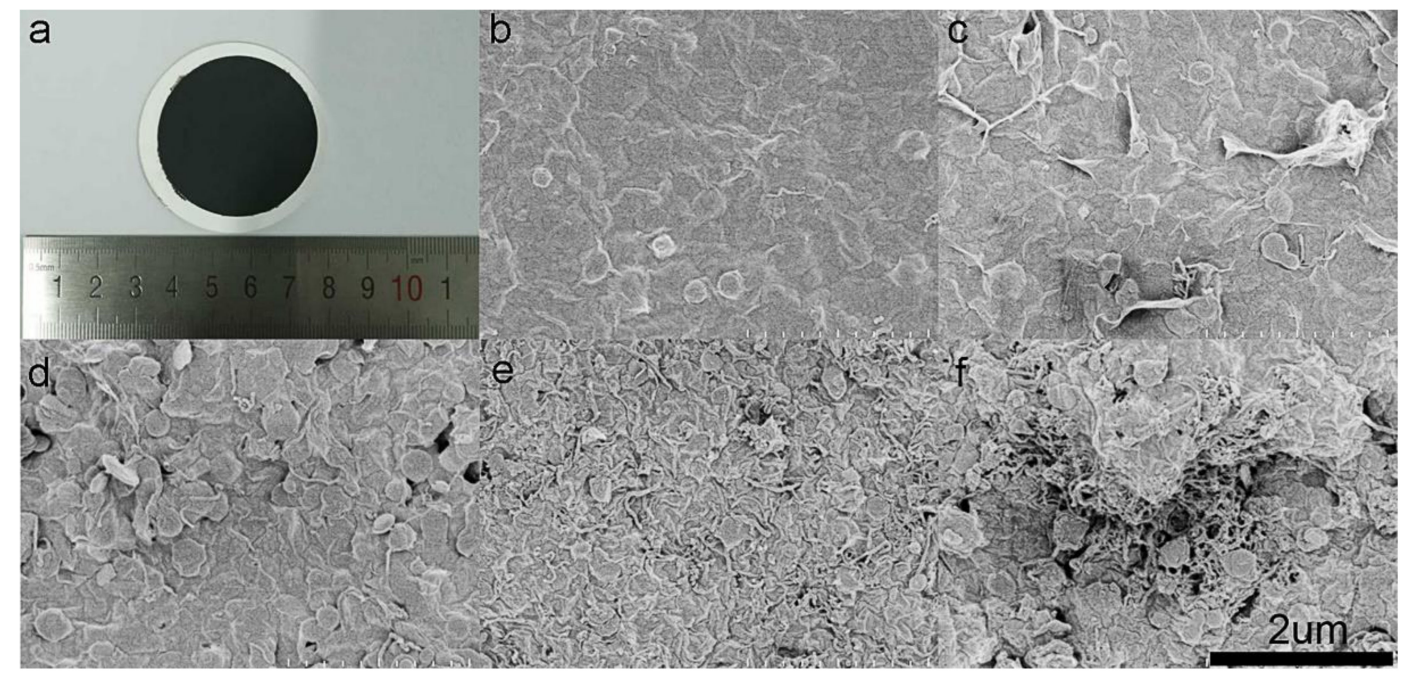

Figure 3. (a) A photograph of the prepared nanocomposite membrane (b-f) SEM images of the Membrane- $X, X=5,2,1,0.5,0.2$, respectively. The scalebar of $(\mathbf{b}-\mathbf{f})$ is $2 \mu \mathrm{m}$.

Figure 5a shows the XRD patterns of the prepared MWCNTs/BNNSs/GO membrane with different mass ratios of GO to $\mathrm{BN}$. Pure GO and $\mathrm{BN}$ membranes were also characterized. The characteristic diffraction peak of pure GO membrane appeared at $10.9^{\circ}$, and the characteristic diffraction peak of the prepared composite membrane appeared at $8.79^{\circ}$ for GO (001) and $26.8^{\circ}$ for $\mathrm{BN}$ (002), indicating that the interlayer space of GO increased from $0.81 \mathrm{~nm}$ to $1.01 \mathrm{~nm}$. The reason for the increased GO interlayer space is that BNNSs and MWCNTs embed in adjacent GO sheets. The interlayer space of BN remained unchanged. The characteristic diffraction peak of MWCNTs was not observable in the membrane. This may due to the fact that MWCNTs were surrounded by GO and BNNSs. When the mass ratio of GO to BN changed, the peak of GO gradually became invisible, in accordance with the SEM results, which may be attributed to the replacement of GO by the BNNSs/GO. In addition, Figure 5b shows the X-ray photoelectron spectroscopy (XPS) survey scan spectra of the prepared membrane, specifying the co-existence of $\mathrm{C}, \mathrm{N}, \mathrm{O}$, and $\mathrm{B}$ elements. The $\mathrm{B}$ 1s peak at $189.8 \mathrm{eV}$ is accredited to BNNSs in the membrane, and it indicated that the BNNSs/GO nanocomposite membrane was formed. 


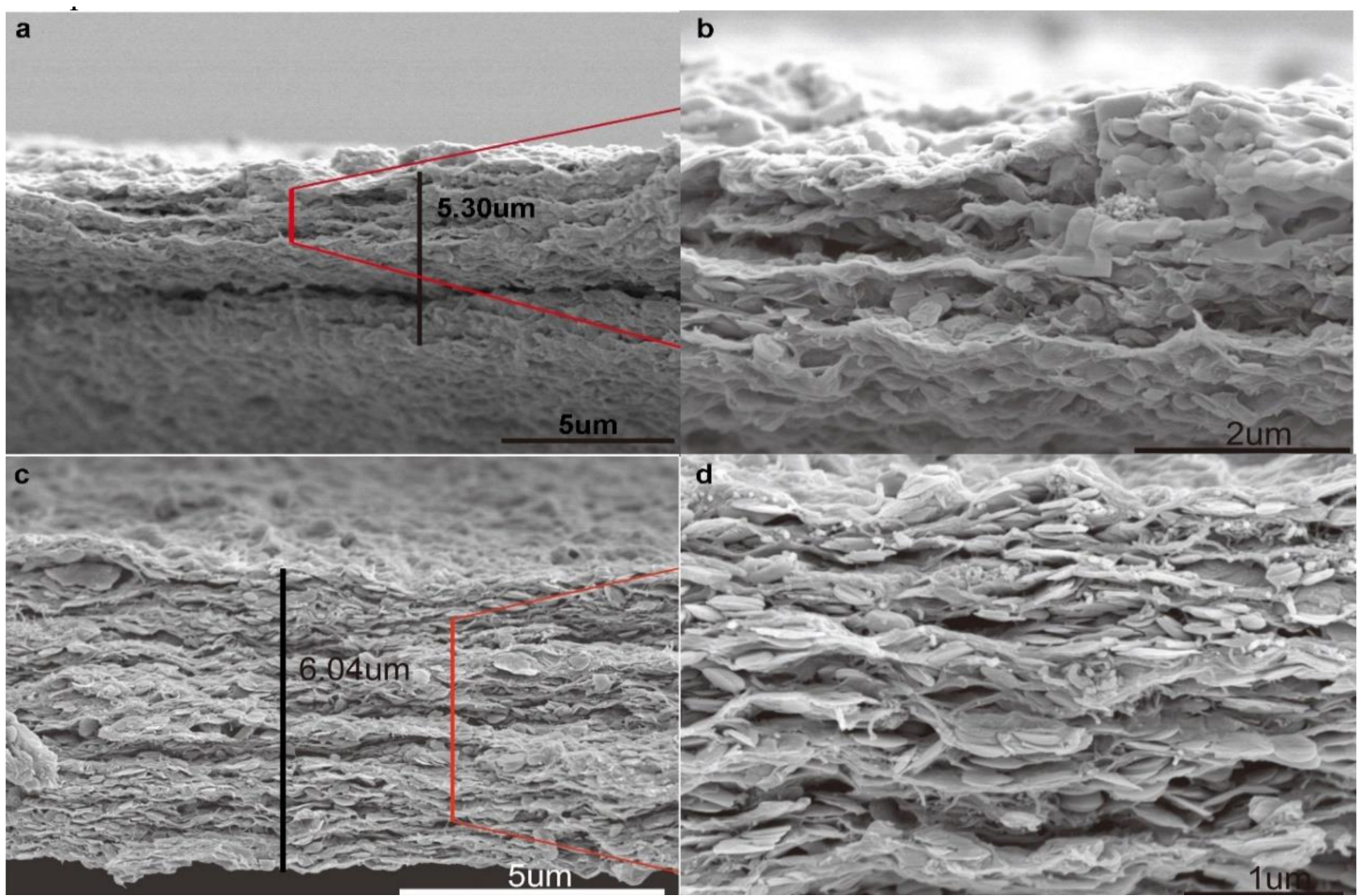

Figure 4. Cross section of the prepared membrane with different volume dispersion. (a,b) $6 \mathrm{~mL}$ dispersion. (c,d) $12 \mathrm{~mL}$ dispersion.

a

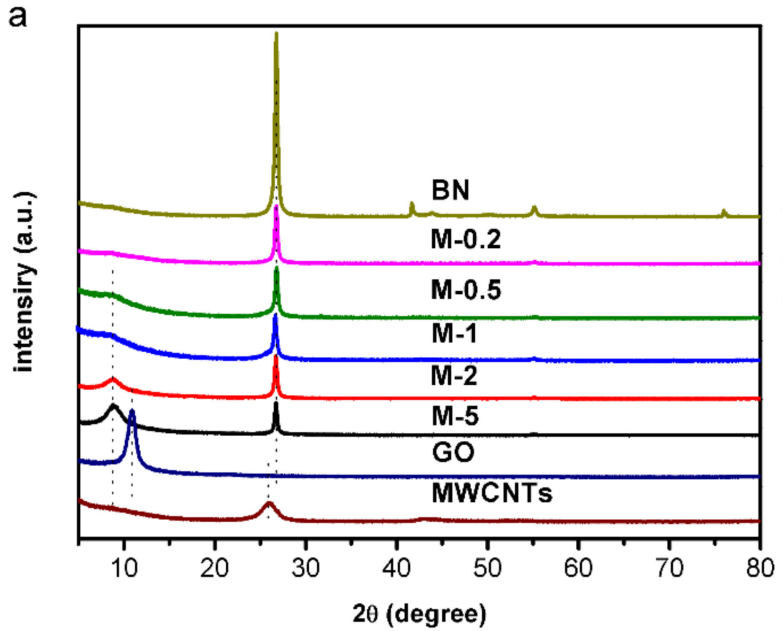

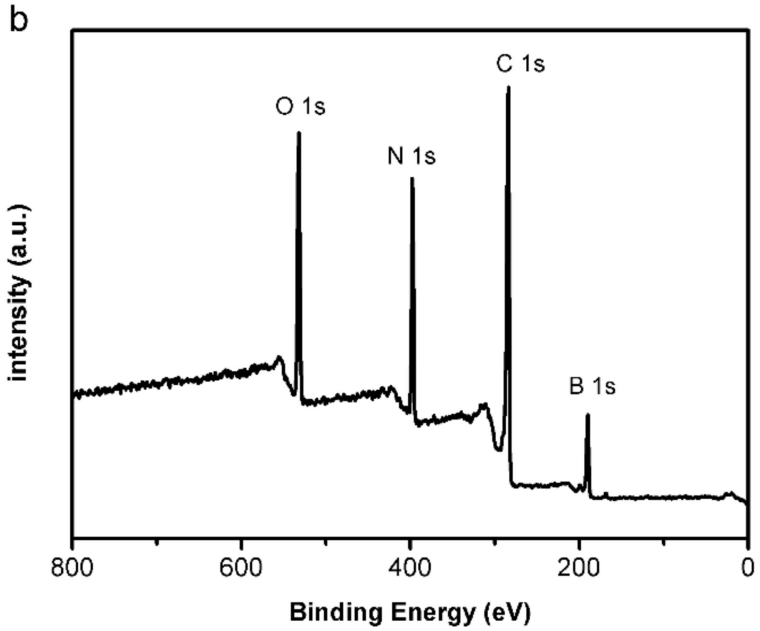

Figure 5. (a) X-ray diffraction (XRD) pattern of Membrane-X and the materials used. (b) X-ray photoelectron spectroscopy (XPS) spectra of the prepared membrane.

The possible contaminants removal process is illustrated in Figure 2c. Due to the similarity between GO and BNNSs in terms of lattice structure, GO and BNNSs easily formed membrane via facile vacuum filtration [33] (Figure 2b). The synergistic effect of the membrane's size exclusion and MWCNTs' adsorption contributed to the successful contaminants' removal. Specifically, the BNNSs/GO skeleton made up the nanosized channel, which prevented the passage of macromolecular contaminants and allowed water flow at the same time. Moreover, the intercalation of MWCNTs increased the interlayer space of the membrane, thus resulting in a faster water flow and the MWCNTs enhanced the adsorption of contaminants. It is also suggested that electrostatic interactions between functional groups on the BNNSs/GO nanosheets and the charged contaminants helped to retain the contaminants [34]. Due to the use of BNNSs, the interlaminar water transportation channel 
became anfractuous, which was beneficial for the removal of contaminants. However, the permeance of the membrane did not decrease due to the increase in interlayer space and the smaller lateral size of BNNSs (100-500 nm) than that of GO (500-1000 nm). With the increasement of BNNSs, the joint point of nanomaterial increased in the layer, leading to the formation of through-thickness cracks which allow filtrate easily across the layer. Therefore, the prepared membrane was able to maintain high permeance and result in high rejection.

\subsection{Membrane Performance}

The UV-Vis absorption spectra of TCH solution $\left(30 \mathrm{mg} \mathrm{L}^{-1}, 10 \mathrm{~mL}\right)$ before and after filtration using the composite membranes with different GO and BNNSs mass ratios are shown in Figure 6a. Figure $6 \mathrm{~b}$ is the standard curve which shows the relationship between maximal absorbance $(261 \mathrm{~nm})$ and concentration of TCH solution. It was obvious that the absorbance of TCH solution after filtration sharply declined which indicated the effective removal of TCH. By absorbance, the rejection to TCH was easily obtained. Moreover, the permeance of the composite membrane was also monitored (Figure 6c). When considering both the rejection to TCH and the permeance, it was concluded that the best performance of the composite membrane was achieved when the mass ratio of GO to BNNSs was 1:2 as the rejection reached $96.1 \%$ which was higher or similar to that in other reports [35,36]. In addition, the permeance was higher than in other reports [37-40] and was $30.2 \mathrm{~L} \mathrm{~m}^{-2} \mathrm{~h}^{-1} \mathrm{bar}^{-1}$. Possible reasons for the increase in permeance are as follows: With an increase in BNNSs, the number of BNNSs/GO nanocomposites increased, and then BNNSs/GO replaced GO as the membrane skeleton. The permeance increased due to the larger interlayer space of BNNSs/GO. However, when the number of BNNSs was too high, BNNSs replaced the BNNSs/GO, resulting in a decrease in the interlayer space and permeance.

When the volume of $\mathrm{TCH}$ increased to $20 \mathrm{~mL}$, the membrane rejection to $\mathrm{TCH}$ was still high and reached $92.8 \%$ (Figure S3). On this basis, a further experiment was performed to test the recycling ability of the membrane. As shown in Figure $7 \mathrm{a}$, the rejection rates of the membrane for TCH was still above $75 \%$ after a cycle of 7 times. This is different from simple adsorption whose rejection to contaminants has a sudden drop [41]. This also demonstrated the good stability of the prepared MWCNTs/BNNSs/GO membrane for the removal of TCH from water. The performance of MWCNTs/BNNSs/GO membrane was compared with pure BN, GO and MWCNTs/GO membrane, and the result was shown in Figure $7 \mathrm{~b}$. The permeance of pure BN membrane was as large as $232.9 \mathrm{~L} \mathrm{~m}^{-2} \mathrm{~h}^{-1}$ bar $^{-1}$, but the rejection to TCH was only $60.1 \%$. In contrast, the pure GO membrane and MWCNTs/GO membrane showed good rejection to TCH which were above $93 \%$, but their permeances were slow (below $8 \mathrm{~L} \mathrm{~m}^{-2} \mathrm{~h}^{-1} \mathrm{bar}^{-1}$ ). The prepared MWCNTs/BNNSs/GO membrane showed both high rejection of TCH and relatively large permeance. Furthermore, the rejection of PVDF polymer substrate to TCH was also explored, but it showed almost no rejection to TCH. Therefore, the membrane's size exclusion is the main reason for the high rejection. 

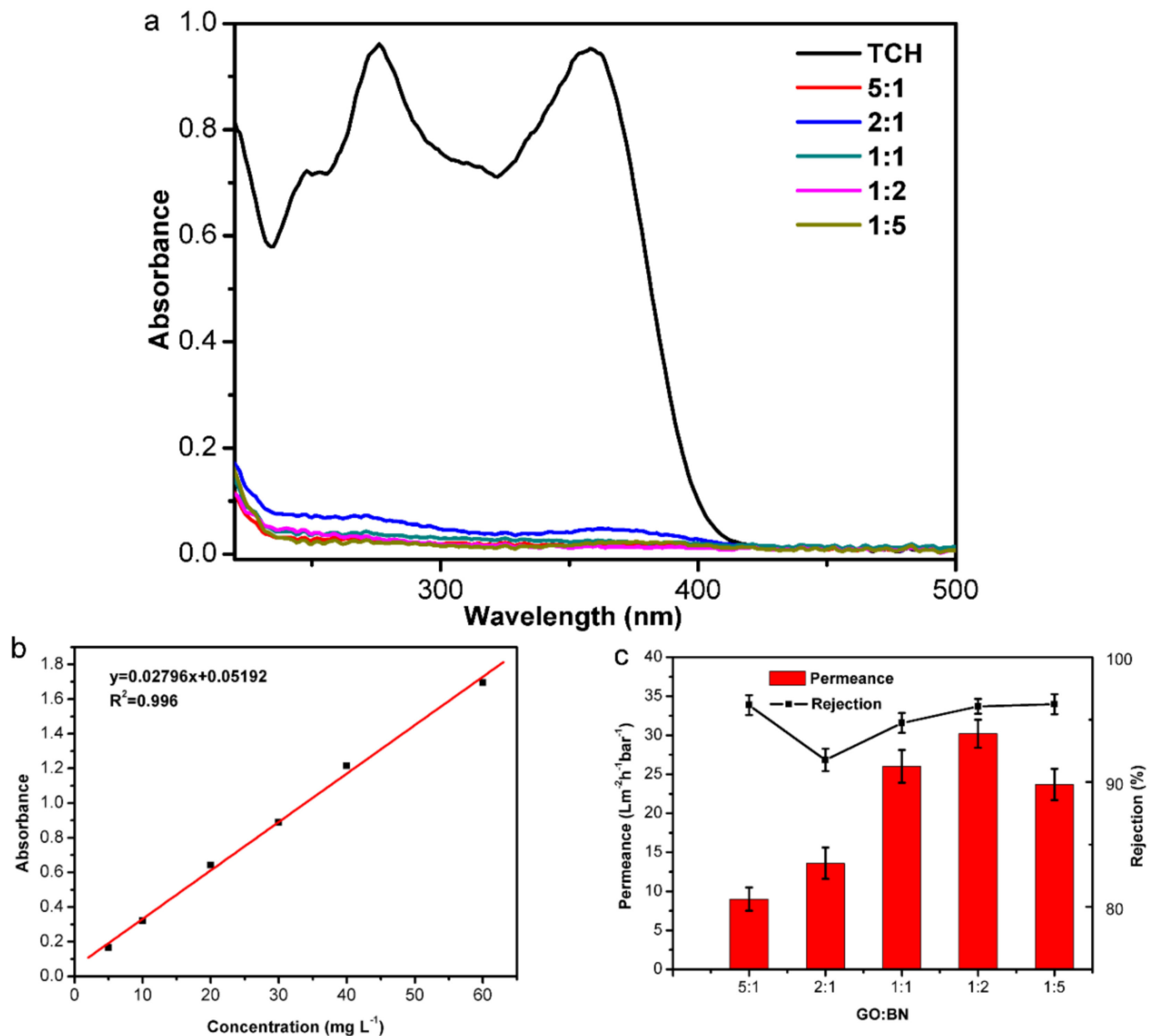

Figure 6. (a) Ultraviolet-visible (UV-Vis) absorption spectra of initial tetracycline hydrochloride (TCH) (concentration of $30 \mathrm{mg} \mathrm{L}^{-1}$ ) and the filtrate through the M-X. (b) standard curve of the concentration of $\operatorname{TCH}\left(5,10,20,30,40,60 \mathrm{mg} \mathrm{L}^{-1}\right)$. (c) Filtration performance of Membrane-X.
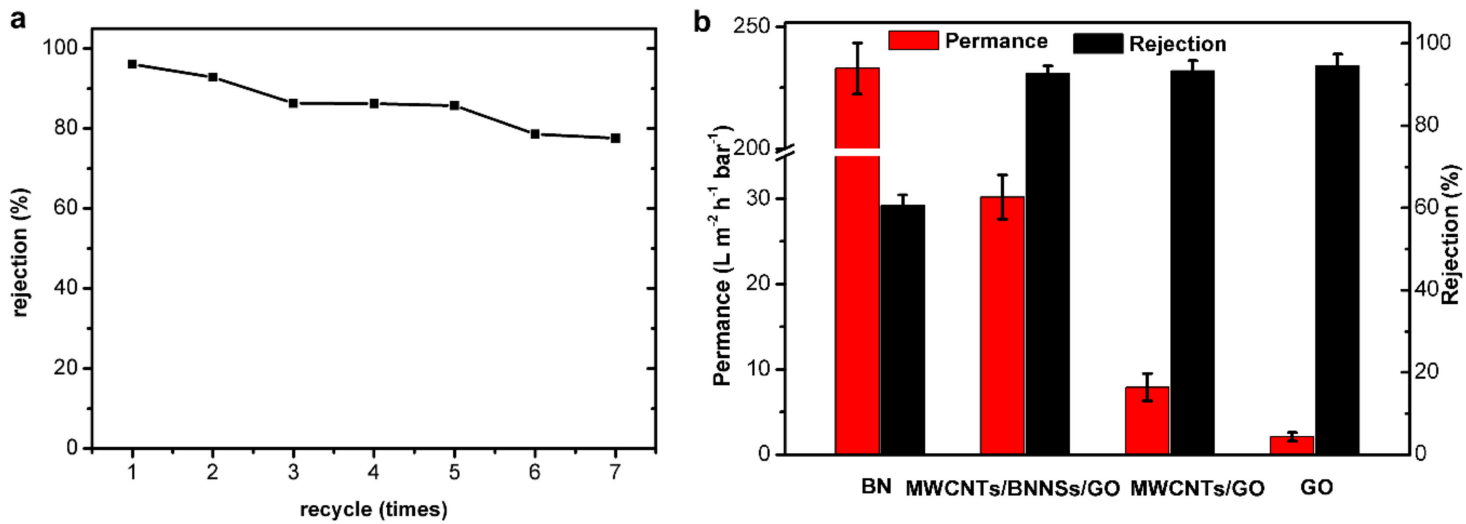

Figure 7. (a) Rejection of the prepared membrane to TCH during 7 times cycle $\left(10 \mathrm{~mL}, 30 \mathrm{mg} \mathrm{L}^{-1} \mathrm{TCH}\right.$ solution was used for each time). (b) Performance of BN, MWCNTs/BNNSs/GO, MWCNTs/GO, GO membrane for removal of TCH.

In order to determine the performance of the membrane in environments such as acidic, alkaline or saline conditions, a series of experiments were performed by adjusting the $\mathrm{pH}$ of the TCH solution or adding salt into it. Figure 8a shows the influence of $\mathrm{pH}$ value on the rejection of $\mathrm{TCH}$, and it was found that the performance of the membrane declined slightly in alkaline solution compared with acid 
or neutral solutions. A possible reason for this is that the hydrochloric in TCH dissociated and reacted with the alkali, then producing salt which made the environment harsher and reduced membrane performance. Although the rejection in alkaline condition declined, it still reached $86.1 \%$. Figure $8 \mathrm{~b}$ shows the effect of different salt concentrations on the membrane performance. It can be seen that the higher the salt concentrations, the lower the membrane performance. This result demonstrated that salts induce a harsher environment when the membrane intercepts TCH from solution. As the color of the TCH solution changed due to the addition of alkaline or salt, reactions may have occurred in the solution. The color of TCH solution was clear and transparent after filtration. It is very likely that electrostatic interactions occurred between metal cations and negatively charged BNNSs, and these electrostatic interactions partly destroyed the interaction between GO and BNNSs, resulting in a decline in membrane performance. However, the membrane was still stable in a salts solution and had a blocking effect on saline ions.

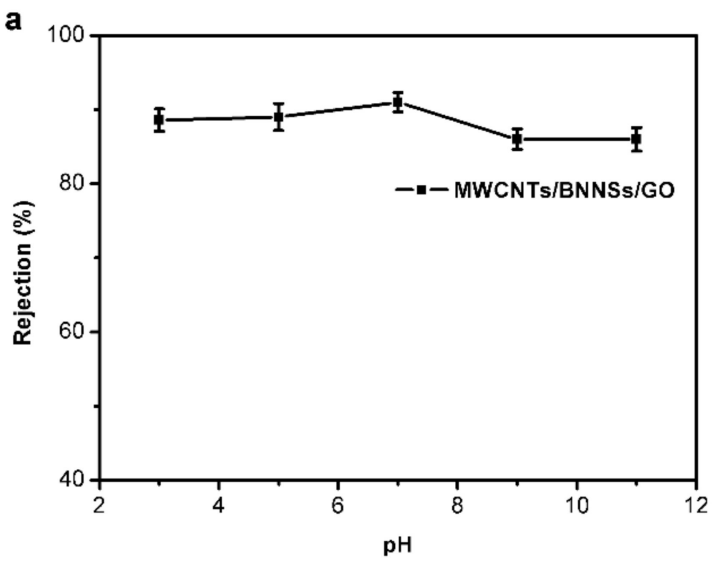

Figure 8. (a) Effect of $\mathrm{pH}$ to the membrane performance. membrane performance.

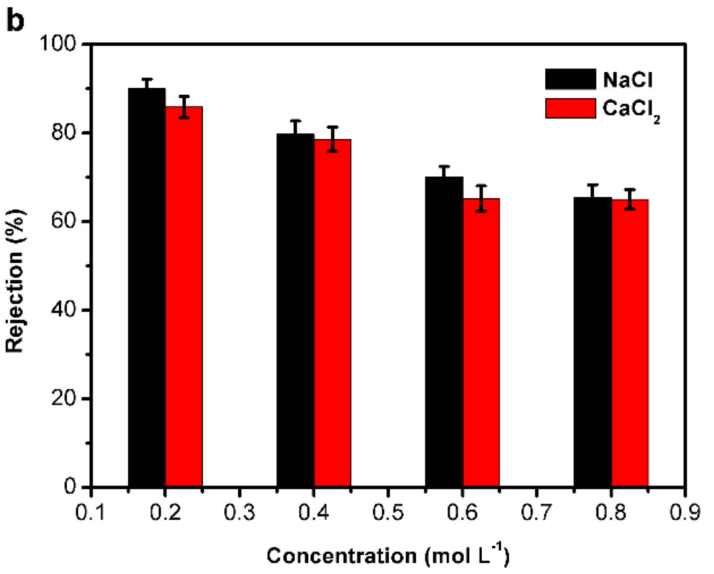

\section{Conclusions}

In summary, a novel BNNSs/GO nanocomposite membrane was developed using a facile method, with a suitable performance for removing antibiotics in water. MWCNTs were used as a filler to increase the interlayer space of the membrane and absorb contaminant molecule. The membrane showed a steady rejection to TCH and a high permeance. Moreover, the membrane was stable in harsh environments such as acidic, alkaline and saline, and was still effective. When the amount of contaminant was increased, the membrane performance was still considerable. The combination of a simple, easy operation preparation process and excellent performance makes this membrane a promising option in water treatment.

Supplementary Materials: The following are available online at http:/ /www.mdpi.com/2079-4991/9/3/386/s1, Figure S1: (a) AFM of the BNNSs, (b) SEM, (c) TEM, and (d) AFM of GO nanosheets; Figure S2: Filtration performance of membrane with different weight of MWCNTs, from group 1 to 5, the weight of MWCNTs was 0.5, 1, 2, 3, $4 \mathrm{mg}$, respectively; Figure S3: (a) UV-Vis absorption spectra of the initial TCH solution and filtrate, the filtrate obtained by filtrating $20 \mathrm{~mL} 30 \mathrm{mg} \mathrm{L}^{-1} \mathrm{TCH}$ using the prepared membrane. (b) Filtration performance

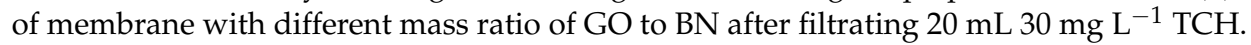

Author Contributions: G.H.: project administration, funding acquisition, experiment design and validation; D.Z.: conducted experiments, data curation and writing; C.W.: conducted experiments and investigation; H.L.: formal analysis and validation; Q.L.: investigation, methodology and validation; H.L.: funding acquisition, resources and supervision.

Funding: This research was funded by the National Natural Science Foundation of China (21605062, 21505057, 51504242), and the Natural Science Foundation of Jiangsu Normal University (15XLR011), and the Priority Academic Program Development of Jiangsu Higher Education Institutions (PAPD), and the Brand Major of Universities in Jiangsu Province, the Top-notch Academic Programs Project of Jiangsu Higher Education Institution (TAPP). 
Conflicts of Interest: The authors declare no conflict of interest.

\section{References}

1. Arenas, N.E.; Melo, V.M. Producción pecuaria y emergencia de antibiótico resistencia en Colombia: Revisión sistemática. Infectio 2018, 22, 110-119. [CrossRef]

2. Pellerito, A.; Ameen, S.M.; Micali, M.; Caruso, G. Antimicrobial Substances for Food Packaging Products: The Current Situation. J. AOAC Int. 2018, 101. [CrossRef] [PubMed]

3. Tamma, P.D.; Avdic, E.; Li, D.X.; Dzintars, K.; Cosgrove, S.E. Association of Adverse Events With Antibiotic Use in Hospitalized Patients. JAMA Intern. Med. 2017, 177, 1308-1315. [CrossRef]

4. $\quad$ Fridkin, S.; Baggs, J.; Fagan, R.; Magill, S.; Pollack, L.A.; Malpiedi, P.; Slayton, R.; Khader, K.; Rubin, M.A.; Jones, M.; et al. Vital Signs: Improving Antibiotic Use Among Hospitalized Patients. MMWR-Morb. Mortal. Wkly. Rep. 2014, 63, 194-200. [PubMed]

5. Ferri, M.; Ranucci, E.; Romagnoli, P.; Giaccone, V. Antimicrobial resistance: A global emerging threat to public health systems. Crit. Rev. Food Sci. 2017, 57, 2857-2876. [CrossRef] [PubMed]

6. Tan, L.; Li, L.Y.; Ashbolt, N.; Wang, X.L.; Cui, Y.X.; Zhu, X.; Xu, Y.; Yang, Y.; Mao, D.Q.; Luo, Y. Arctic antibiotic resistance gene contamination, a result of anthropogenic activities and natural origin. Sci. Total Environ. 2018, 621, 1176-1184. [CrossRef] [PubMed]

7. Huo, T.I. The First Case of Multidrug-resistant NDM-1-harboring Enterobacteriaceae in Taiwan: Here Comes the Superbacteria! J. Chin. Med. Assoc. 2010, 73, 557-558. [CrossRef]

8. Tong, S.; Pan, J.; Lu, S.; Tang, J. Patient compliance with antimicrobial drugs: A Chinese survey. Am. J. Infect. Control 2018, 46, E25-E29. [CrossRef] [PubMed]

9. Zhang, L.-H.; He, Y.-W.; Chen, M.; Gao, M.; Qiu, T.-L.; Wang, X.-M. Pollution Characteristics of Antibiotic Resistant Bacteria from Atmospheric Environment of Animal Feeding Operations. Huan Jing Ke Xue 2016, 37, 4531-4537. [CrossRef] [PubMed]

10. Casanova, L.M.; Sobsey, M.D. Antibiotic-Resistant Enteric Bacteria in Environmental Waters. Water 2016, 8, 561. [CrossRef]

11. Alygizakis, N.A.; Gago-Ferrero, P.; Borova, V.L.; Pavlidou, A.; Hatzianestis, I.; Thomaidis, N.S. Occurrence and spatial distribution of 158 pharmaceuticals, drugs of abuse and related metabolites in offshore seawater. Sci. Total Environ. 2016, 541, 1097-1105. [CrossRef] [PubMed]

12. Homaeigohar, S.; Elbahri, M. Graphene membranes for water desalination. NPG Asia Mater. 2017, 9, e427. [CrossRef]

13. Mi, B. Graphene Oxide Membranes for Ionic and Molecular Sieving. Science 2014, 343, 740-742. [CrossRef] [PubMed]

14. Cohen-Tanugi, D.; Grossman, J.C. Water Desalination across Nanoporous Graphene. Nano Lett. 2012, 12, 3602-3608. [CrossRef] [PubMed]

15. Fan, Y.; Yang, Z.; Hua, W.X.; Liu, D.; Tao, T.; Rahman, M.M.; Lei, W.W.; Huang, S.M.; Chen, Y. Functionalized Boron Nitride Nanosheets/Graphene Interlayer for Fast and Long-Life Lithium-Sulfur Batteries. Adv. Energy Mater. 2017, 7, 6. [CrossRef]

16. Falin, A.; Cai, Q.R.; Santos, E.J.G.; Scullion, D.; Qian, D.; Zhang, R.; Yang, Z.; Huang, S.M.; Watanabe, K.; Taniguchi, T.; et al. Mechanical properties of atomically thin boron nitride and the role of interlayer interactions. Nat. Commun. 2017, 8, 9. [CrossRef] [PubMed]

17. Hirunpinyopas, W.; Prestat, E.; Worrall, S.D.; Haigh, S.J.; Dryfe, R.A.W.; Bissett, M.A. Desalination and Nanofiltration through Functionalized Laminar $\mathrm{MoS}_{2}$ Membranes. ACS Nano 2017, 11, 11082-11090. [CrossRef] [PubMed]

18. Shi, J.P.; Tong, R.; Zhou, X.B.; Gong, Y.; Zhang, Z.P.; Ji, Q.Q.; Zhang, Y.; Fang, Q.Y.; Gu, L.; Wang, X.N.; et al. Temperature-Mediated Selective Growth of $\mathrm{MoS}_{2} / \mathrm{WS}_{2}$ and $\mathrm{WS}_{2} / \mathrm{MoS}_{2}$ Vertical Stacks on Au Foils for Direct Photocatalytic Applications. Adv. Mater. 2016, 28, 10664. [CrossRef] [PubMed]

19. Pan, L.; Liu, Y.T.; Xie, X.M.; Ye, X.Y. Facile and Green Production of Impurity-Free Aqueous Solutions of WS2 Nanosheets by Direct Exfoliation in Water. Small 2016, 12, 6703-6713. [CrossRef] [PubMed]

20. Fathizadeh, M.; Xu, W.L.; Zhou, F.; Yoon, Y.; Yu, M. Graphene Oxide: A Novel 2-Dimensional Material in Membrane Separation for Water Purification. Adv. Mater. Interfaces 2017, 4. [CrossRef] 
21. Tang, X.; Wang, Z.; Wang, Y. Visible active $\mathrm{N}$-doped $\mathrm{TiO}_{2} /$ reduced graphene oxide for the degradation of tetracycline hydrochloride. Chem. Phys. Lett. 2018, 691, 408-414. [CrossRef]

22. Jiao, S.; Xu, Z. Non-Continuum Intercalated Water Diffusion Explains Fast Permeation through Graphene Oxide Membranes. ACS Nano 2017, 11, 11152-11161. [CrossRef] [PubMed]

23. Cheng, C.; Jiang, G.; Garvey, C.J.; Wang, Y.; Simon, G.P.; Liu, J.Z.; Li, D. Ion transport in complex layered graphene-based membranes with tuneable interlayer spacing. Sci. Adv. 2016, 2. [CrossRef] [PubMed]

24. Park, H.B.; Kamcev, J.; Robeson, L.M.; Elimelech, M.; Freeman, B.D. Maximizing the right stuff: The trade-off between membrane permeability and selectivity. Science 2017, 356. [CrossRef] [PubMed]

25. Yanan, L.; Yanlei, S.; Jingyuan, G.; Jialin, C.; Runnan, Z.; Mingrui, H.; Kang, G.; Linjie, Z.; Zhongyi, J. 2D Heterostructure Membranes with Sunlight-Driven Self-Cleaning Ability for Highly Efficient Oil-Water Separation. Adv. Funct. Mater. 2018, 28, 1706545. [CrossRef]

26. Jingjing, Y.; Dian, G.; Guihua, L.; Gaofeng, Z.; Qiyan, W.; Yelei, Z.; Guojuan, L.; Ping, W.; Evgeny, V.; Zheng, P.; et al. Self-Assembly of Thiourea-Crosslinked Graphene Oxide Framework Membranes toward Separation of Small Molecules. Adv. Mater. 2018, 30, 1705775. [CrossRef]

27. Liu, D.; Zhang, M.; Xie, W.; Sun, L.; Chen, Y.; Lei, W. Porous $\mathrm{BN} / \mathrm{TiO}_{2}$ hybrid nanosheets as highly efficient visible-light-driven photocatalysts. Appl. Catal. B-Environ. 2017, 207, 72-78. [CrossRef]

28. Abdikheibari, S.; Lei, W.; Dumee, L.F.; Milne, N.; Baskaran, K. Thin film nanocomposite nanofiltration membranes from amine functionalized-boron nitride/polypiperazine amide with enhanced flux and fouling resistance. J. Mater. Chem. A 2018, 6, 12066-12081. [CrossRef]

29. Razmjou, A.; Resosudarmo, A.; Holmes, R.L.; Li, H.; Mansouri, J.; Chen, V. The effect of modified $\mathrm{TiO}_{2}$ nanoparticles on the polyethersulfone ultrafiltration hollow fiber membranes. Desalination 2012, 287, 271-280. [CrossRef]

30. Gonzalez-Ortiz, D.; Pochat-Bohatier, C.; Gassara, S.; Cambedouzou, J.; Bechelany, M.; Miele, P. Development of novel h-BNNS/PVA porous membranes via Pickering emulsion templating. Green Chem. 2018, 20, 4319-4329. [CrossRef]

31. Zhang, L.S.; Fan, W.; Liu, T.X. Flexible hierarchical membranes of $\mathrm{WS}_{2}$ nanosheets grown on graphene-wrapped electrospun carbon nanofibers as advanced anodes for highly reversible lithium storage. Nanoscale 2016, 8, 16387-16394. [CrossRef] [PubMed]

32. Lei, W.W.; Mochalin, V.N.; Liu, D.; Qin, S.; Gogotsi, Y.; Chen, Y. Boron nitride colloidal solutions, ultralight aerogels and freestanding membranes through one-step exfoliation and functionalization. Nat. Commun. 2015, 6, 8849. [CrossRef] [PubMed]

33. Shi, G.; Hanlumyuang, Y.; Liu, Z.; Gong, Y.; Gao, W.; Li, B.; Kono, J.; Lou, J.; Vajtai, R.; Sharma, P.; et al. Boron Nitride-Graphene Nanocapacitor and the Origins of Anomalous Size-Dependent Increase of Capacitance. Nano Lett. 2014, 14, 1739-1744. [CrossRef] [PubMed]

34. Huang, L.; Chen, J.; Gao, T.T.; Zhang, M.; Li, Y.R.; Dai, L.M.; Qu, L.T.; Shi, G.Q. Reduced Graphene Oxide Membranes for Ultrafast Organic Solvent Nanofi ltration. Adv. Mater. 2016, 28, 8669-8674. [CrossRef] [PubMed]

35. Zereshki, S.; Daraei, P.; Shokri, A. Application of edible paraffin oil for cationic dye removal from water using emulsion liquid membrane. J. Hazard. Mater. 2018, 356, 1-8. [CrossRef] [PubMed]

36. Hu, M.; Mi, B. Enabling Graphene Oxide Nanosheets as Water Separation Membranes. Environ. Sci. Technol. 2013, 47, 3715-3723. [CrossRef] [PubMed]

37. Li, S.; Luo, J.; Wan, Y. Regenerable biocatalytic nanofiltration membrane for aquatic micropollutants removal. J. Membr. Sci. 2018, 549, 120-128. [CrossRef]

38. Li, W.; Wu, W.; Li, Z. Controlling Interlayer Spacing of Graphene Oxide Membranes by External Pressure Regulation. Acs Nano 2018, 12, 9309-9317. [CrossRef] [PubMed]

39. Xu, W.L.; Fang, C.; Zhou, F.; Song, Z.; Liu, Q.; Qiao, R.; Yu, M. Self-Assembly: A Facile Way of Forming Ultrathin, High-Performance Graphene Oxide Membranes for Water Purification. Nano Lett. 2017, 17, 2928-2933. [CrossRef] [PubMed]

40. Wang, Y.; Li, L.; Wei, Y.; Xue, J.; Chen, H.; Ding, L.; Caro, J.; Wang, H. Water Transport with Ultralow Friction through Partially Exfoliated g- $\mathrm{C}_{3} \mathrm{~N}_{4}$ Nanosheet Membranes with Self-Supporting Spacers. Angew. Chem.-Int. Edit. 2017, 56, 8974-8980. [CrossRef] [PubMed] 
41. Fu, H.; Li, X.; Wang, J.; Lin, P.; Chen, C.; Zhang, X.; Suffet, I.H. Activated carbon adsorption of quinolone antibiotics in water: Performance, mechanism, and modeling. J. Environ. Sci. 2017, 56, 145-152. [CrossRef] [PubMed]

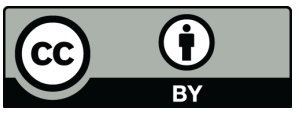

(C) 2019 by the authors. Licensee MDPI, Basel, Switzerland. This article is an open access article distributed under the terms and conditions of the Creative Commons Attribution (CC BY) license (http:/ / creativecommons.org/licenses/by/4.0/). 